\title{
Obscure gastrointestinal bleeding due to Meckel's diverticulum: unusual capsule endoscopic finding as polyp-like lesion
}

Lower gastrointestinal bleeding is a common complication of Meckel's diverticulum. Its location within the small bowel, usually 2 feet $(60 \mathrm{~cm})$ from the ileocecal valve, makes it difficult to study and not easily accessible with a traditional endoscope. The use of multiple diagnostic modalities may give a false negative result, and capsule endoscopy can be an alternative procedure. In young children, who are not able to swallow the capsule, the capsule can be delivered via gastroscopy with an overtube, with the patient under intravenous anesthesia [1]. Reported complication rates of capsule endoscopy (retention of capsule in stomach and intestine) have ranged from $0.3 \%$ to $20 \%[1,2]$. Retention may necessitate endoscopic retrieval or surgical removal [1], or observation may suffice so long as the patient is asymptomatic. Endoscopy may showed the presence of a false lumen [3], a diverticular-like orifice [4], or a blood-filled structure [5]. We report the case of a 15-year-old male patient referred to our department with recurrent lower gastrointestinal bleeding with a hemoglobin concentration of $5 \mathrm{gm} / \mathrm{L}$. He had several diagnostic examinations including computed tomography and magnetic resonance imaging of the abdomen, colonoscopy, Meckel's scan (technetium $99 \mathrm{~m}$ pertechnetate) and red blood cell scan which detected no relevant abnormality. A wireless video capsule endoscopy study revealed a polyp-like lesion, secondary to everted diverticular mucosa, protruding from a false lumen presenting as a dark halo zone in the mid portion of the small bowel ( Fig. 1 a), 4.5 hours after capsule introduction, with oozing of blood on a picture taken a few minutes later ( Fig.1b). An exploratory laparotomy was performed and a Meckel's diverticulum with a palpable mass ( Fig. 1 c) was found. Segmental resection of the bowel was performed. Examination of the specimen revealed everted diverticular mucosa ( $\bullet$ Fig. 1 d), which is compatible with the capsule endoscopic finding ( $\odot$ Fig. 1 a). An intraoperative finding of Meckel's diverticulum with early examination of the surgical
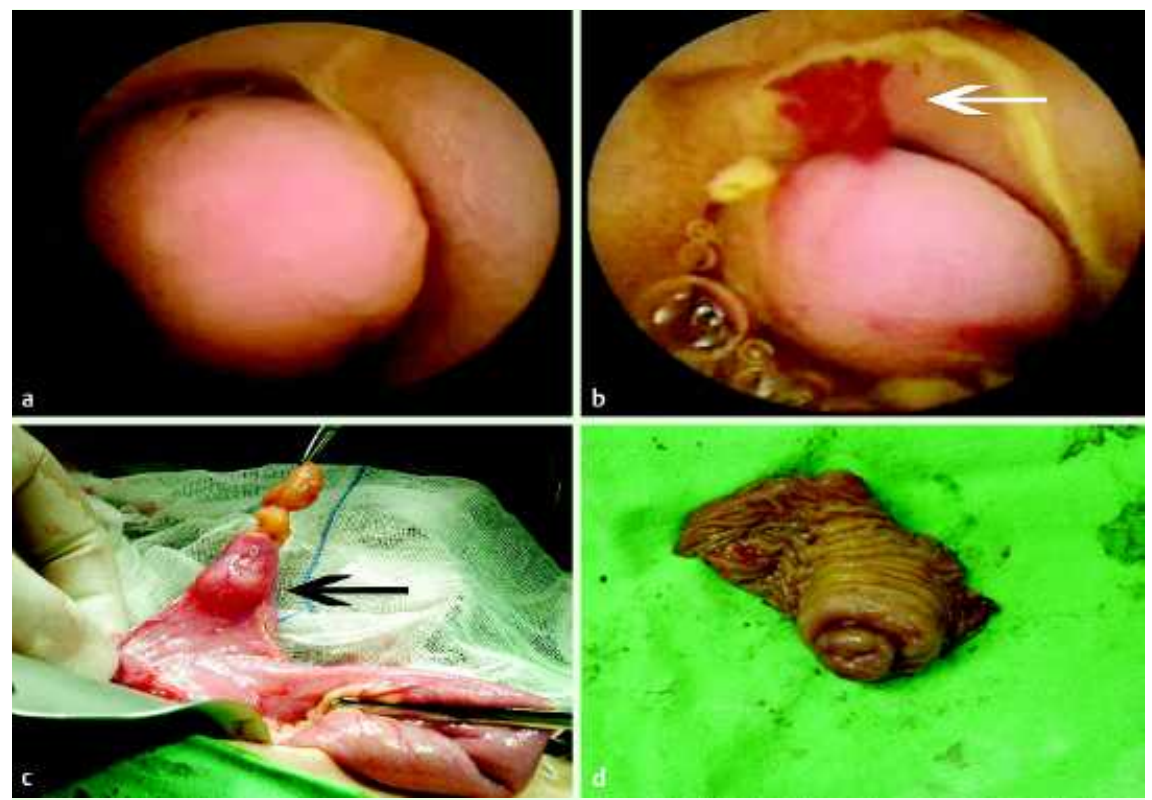

Fig. 1 a Capsule endoscopy showed a protruding polyp-like lesion from the lumen with blood oozing (b, white arrow). c Surgical finding showed a Meckel's diverticulum with a palpable mass (black arrow), and the cut section of the resected small bowel with Meckel's diverticulum showed protruding everted diverticular mucosa (d).

specimen can avoid further unnecessary palpatory and endoscopic exploration of the entire small bowel.

\section{Endoscopy_UCTN_Code_CCL_1AC_2AF}

\section{E. D. Sy ${ }^{1}$, M.-D. Chen ${ }^{1}$, Y.-J. Yang ${ }^{2}$,}

\section{Y.-S. Shan ${ }^{1}$}

Department of Surgery, National Cheng Kung University Hospital, Tainan, Taiwan 2 Department of Pediatrics, National Cheng Kung University Hospital, Tainan, Taiwan

\section{References}

1 Moy L, Levine J. Wireless capsule endoscopy in the pediatric age group: experience and complications. J Pediatr Gastroenterol Nutr 2007; 44: 516-520

2 Guilhon de Araujo Sant'Anna AM, Dubois J, Miron MC, Seidman EG. Wireless capsule endoscopy for obscure small-bowel disorders: final results of the first pediatric controlled trial. Clin Gastroenterol Hepatol 2005; 3: 264-270

3 Moon JH, Park CH, Kim JH et al. Meckel's diverticulum bleeding detected by capsule endoscopy. Gastrointest Endosc 2006; 63: 702; discussion 703
4 Golder S, Schmidt J, Kolmsee P et al. Identification of a Meckel's diverticulum by wireless capsule endoscopy. Endoscopy 2005; 37: 608

5 Mylonaki M, MacLean D, Fritscher-Ravens A, Swain $P$. Wireless capsule endoscopic detection of Meckel's diverticulum after nondiagnostic surgery. Endoscopy 2002; 34: $1018-1020$

Bibliography

DOI $10.1055 / \mathrm{s}-2008-1077435$

Endoscopy 2008; 40: E203

(c) Georg Thieme Verlag KG Stuttgart · New York . ISSN 0013-726X

Corresponding author

\section{E. D. Sy, MD}

Department of Surgery

Section of Pediatric Surgery

National Cheng Kung University Hospital

138 Sheng Li Road

Tainan

Taiwan

Fax: +886-6-2766676

edsy@mail.ncku.edu

edsyfalcon2@yahoo.com.tw 